\title{
The Experiences in a Toxicology Unit: A Review of 623 Cases
}

\author{
Ramazan Koylu, ${ }^{\mathrm{a}, \mathrm{d}}$, Zerrin Defne Dundara, Oznur Koylu ${ }^{\mathrm{b}}$, Emine Akincia, \\ Nazire Belgin Akillia, Mustafa Onder Gonen ${ }^{\mathrm{a}}$, Basar Cander ${ }^{\mathrm{c}}$
}

\begin{abstract}
Background: To evaluate the etiological and demographic characteristics of adult poisoning patients followed up in a toxicology unit in Konya, Turkey.

Methods: Patients ( $\geq 15$ years old) followed up with the diagnosis of poisoning in our toxicology unit in 2011 were included in this retrospective study. The patients' medical records were investigated. Age, gender, medical history, the first medical center the patient had been admitted to, the routes and causes of poisoning, the toxins involved, the number of the pills taken, treatments, complications, the length of stay in the hospital and the outcome were recorded.
\end{abstract}

Results: A total of 623 patients were included in the study. The mean age of patients was $28.1 \pm 15.1$. Four hundred and forty-five $(71.4 \%)$ of patients were female, $541(86.9 \%)$ of them were poisoned via the oral route and $75(12.0 \%)$ of them were poisoned by inhalation. The causes of poisoning were drugs in $408(65.5 \%)$ patients, pesticides/insecticides in $58(9.3 \%)$ patients and carbon monoxide in $49(7.9 \%)$ patients. The commonly used drugs were as follows: analgesics (57.2\%), antidepressants (25.4\%) and gastrointestinal system drugs (15.8\%). The poisonings were suicidal in 489 (78.5\%) patients, accidental in $120(19.3 \%)$ patients and overdose in $14(2.2 \%)$ patients. The number of women was higher in the suicide group. At the end of the treatment, $604(97.0 \%)$ of the patients were discharged and $3(0.4 \%)$ of them died. The duration of followup was $39.2 \pm 37.5 \mathrm{~h}$.

Conclusion: The most common causes of poisoning are drugs,

\footnotetext{
Manuscript accepted for publication November 19, 2013

${ }^{a}$ Konya Training and Research Hospital, Emergency Department, Konya, Turkey

${ }^{\mathrm{b}}$ Konya Training and Research Hospital, Biochemistry Department, Konya, Turkey

${ }^{\mathrm{c}}$ Necmettin Erbakan University Meram Faculty of Medicine,

Emergency Medicine Department, Konya, Turkey

${ }^{\mathrm{d} C}$ Corresponding author: Ramazan Koylu, Konya Training and Research

Hospital, Emergency Department, Konya, Turkey.

Email: drkoylu@yahoo.com
}

doi: http://dx.doi.org/10.4021/jocmr1687w pesticides/insecticides and carbon monoxide. Health and educational policies at a national level are needed in order to prevent this medicosocial problem. Furthermore, specially equipped toxicology units should be constructed for the treatment and follow-up of the poisoned patients in order to reduce the morbidity and mortality to a significant extent.

Keywords: Toxicology; Poisoning; Epidemiology; Suicide

\section{Introduction}

Suicidal and accidental poisonings are important and frequent reasons for admissions to the emergency units. The rate of poisoning in USA was reported to be $479 / 100,000$ in 2011 and the rate of poisoning-related deaths was reported to be $17 / 100,000$ in $2010[1,2]$. In contrast to the previous years, poisoning has become the most frequent reason for accidental deaths with a rate surpassing motor vehicle-related mortalities [3]. Different morbidity and mortality rates due to poisoning have been reported worldwide [4-7].

The etiological and demographic characteristics of poisoning cases differ even in different geographical regions of the same country. Various outcomes have been reported in studies conducted in different regions of our country as well. In general, the poisonings in our country are suicidal and are common amongst women. However, pesticides are important causes of poisoning in farming regions, and carbon monoxide and fungi are important causes of poisoning in some other regions [8-12].

The aim of this retrospective study performed in 2011 was to present the etiological and demographic characteristics of poisoned adult patients followed up in the toxicology unit of the emergency department, in a training and research hospital in Konya, a city of the Middle Anatolian Region of Turkey.

\section{Methods}

Patients $(\geq 15$ years and older) who were followed up with 


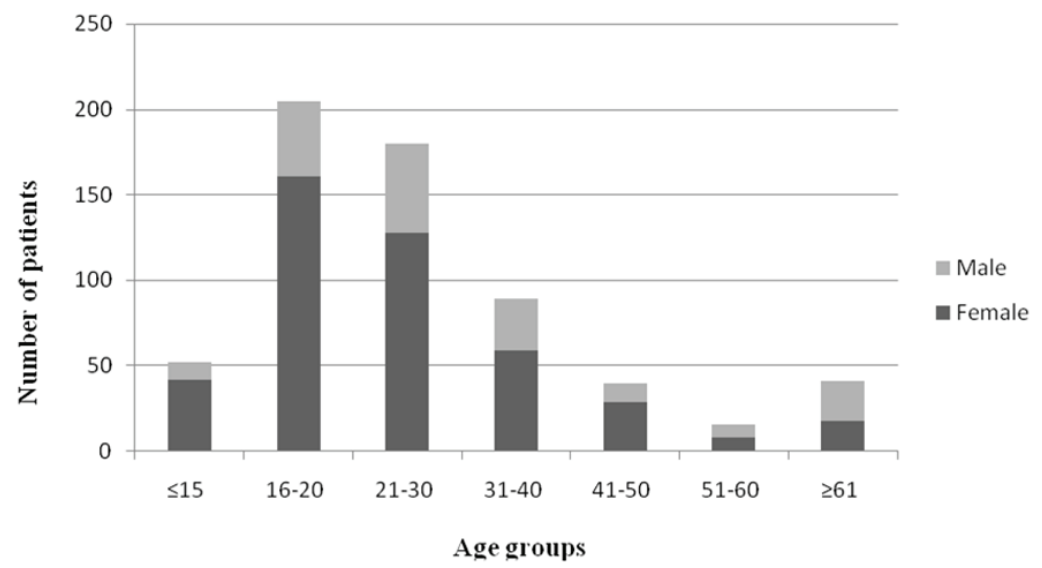

Figure 1. The gender distribution of the patients with regard to the age groups.

the diagnosis of poisoning in our toxicology unit in 2011, were included in this retrospective study. The patients' medical records were investigated. Age, gender, medical history, the first medical center the patient had been admitted to, the route and cause of poisoning, the toxins, the number of the pills taken, treatments, complications, the length of stay in the hospital and the outcome were recorded.

Our toxicology unit began functioning under the operation of the emergency unit in March 2011 with a 6-bed capacity. Every bed is equipped with a bedside unit including a monitor, a stationary aspirator, an oxygen source and a medical air source compatible with a ventilator. There are two mechanical ventilators and one bedside hemodialysis/ hemoperfusion instrument in the toxicology unit. The multidrug test could not be performed due to some technical issues during the study, but the levels of the drugs were measured in the central biochemistry laboratory of our hospital throughout the study. Therefore, the multi-drug detection of the patients could not be investigated.

The toxins involved in our study were divided into 8 groups including drugs, pesticides/insecticides, rodenticides, carbon monoxide, foods, corrosives, others (narcotics, alcohol, and so on) and unknowns. The drugs were also divided into 12 groups including analgesics, antibiotics, antihistamines, decongestants, antidepressants, other psychoactive drugs (antipsychotics, benzodiazepines, barbiturates, and so on), anticonvulsants, antidiabetics, cardiovascular system drugs, gastrointestinal system drugs, others (vitamins, hormones, and so on) and unknowns. The patients were divided into 3 groups according to the cause of poisoning (suicidal, accidental and overdose).

The descriptive statistics were performed using the SPSS version 16.0 (SPSS Inc., Chicago, USA). The data were expressed as frequencies, percentages and mean $\pm \mathrm{SD}$. The categorical data were compared using the chi-square test and the constant data were compared using the Student's t

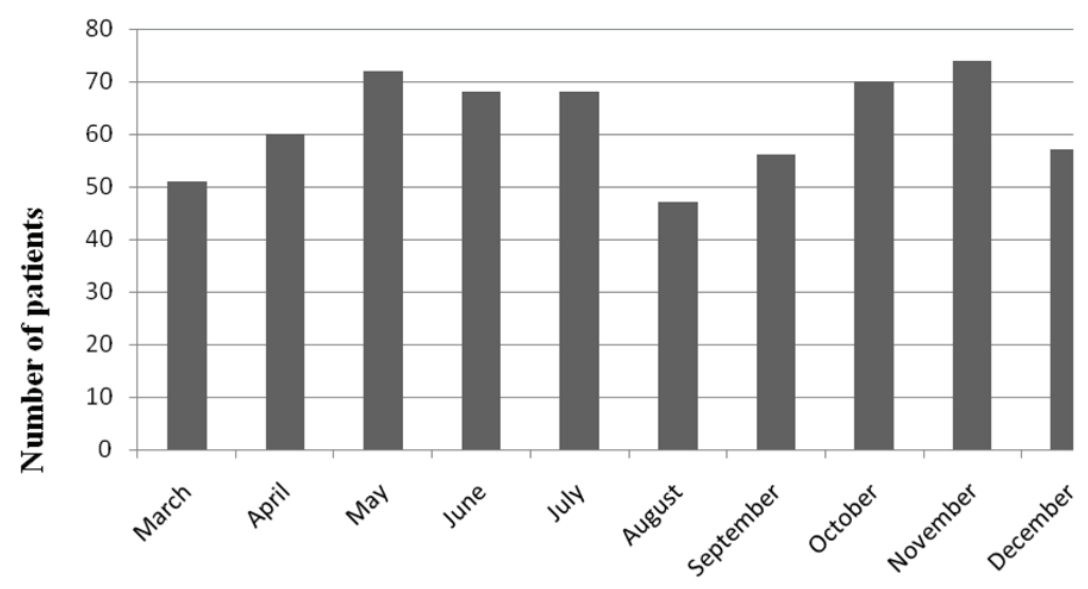

Months

Figure 2. The distribution of poisoning cases according to months. 
Table 1. Drug Groups Involved in the Poisoning of 418 Patients

\begin{tabular}{ll}
\hline & $\mathbf{n}(\mathbf{\%})^{*}$ \\
\hline Analgesics & $239(57.2)$ \\
Antidepressants & $106(25.4)$ \\
Gastrointestinal system drugs & $66(15.8)$ \\
Antihistamines & $60(13.4)$ \\
Antibiotics & $54(12.9)$ \\
Decongestants & $49(11.7)$ \\
Cardiovascular system drugs & $37(8.9)$ \\
Other pyschoactive drugs & $36(8.6)$ \\
Anticonvulsants & $18(4.3)$ \\
Antidiabetics & $16(3.8)$ \\
Others & $69(16.5)$ \\
Unknown & $24(5.7)$
\end{tabular}

test or the Mann-Whitney U test. A P value of $<0.05$ was evaluated as statistically significant.

\section{Results}

The medical charts of 641 patients who were followed up in our toxicology unit in 2011 were retrospectively investigated. Eleven patients with missing information and 7 patients who were determined not have been poisoning cases were excluded from the study. A total of 623 patients that fulfilled the inclusion criteria were included in the study. One hundred and seventy-eight $(28.6 \%)$ of patients were male and $445(71.4 \%)$ of them were female. The mean age was 28.1 \pm 15.1 (range $13-90$ ). The $16-20$ age group included the maximum number of cases, which was $205(32.9 \%)$. The number of female patients was statistically significantly higher than the number of male patients in all groups, except for the $51-60$ and the $\geq 61$ age groups $(\mathrm{P}<0.001)$. Figure 1 shows the age groups and the gender distribution of the patients. The distribution of poisoning cases within months was not different (Fig. 2).

Six hundred and four $(97.0 \%)$ of patients did not have a history of additional disease, while $12(1.9 \%)$ of them had at least one systemic disease such as diabetes mellitus or hypertension. Seven $(1.1 \%)$ patients had various psychiatric disorders. Fifteen $(3.4 \%)$ women were pregnant. Four hundred and five $(65.0 \%)$ of patients had presented to our emergency unit directly, while the other $218(35.0 \%)$ patients had been referred from other medical centers.

Among 623 patients, $541(86.9 \%)$ of them were poi- soned via the oral route, $75(12.0 \%)$ of them were poisoned by inhalation, $5(0.8 \%)$ of them were poisoned dermally, and $2(0.3 \%)$ of them were poisoned via the parenteral route. The poisoning agents were drugs in $408(65.5 \%)$ patients, pesticides/insecticides in 58 (9.3\%) patients, carbon monoxide in 49 (7.9\%) patients, foods in $28(4.5 \%)$ patients, rodenticides in $12(1.9 \%)$ patients, corrosives in $3(0.5 \%)$ patients, and other substances such as alcohol or narcotics in 13 (2.1\%) patients. Multiple substances from several groups were the poisoning agents in $14(2.2 \%)$ patients. Thirty-eight (6.1\%) patients had stated that they had been poisoned via the oral route, but no anamnesis could be obtained regarding the substance of poisoning.

According to the number of exposed active substances, the poisoning occurred due to 1 active substance in 373 $(59.9 \%)$ patients, 2 substances in $86(13.8 \%)$ patients, 3 substances in $55(8.8 \%)$ patients, 4 substances in $27(4.3 \%)$ patients, 5 substances in $11(1.8 \%)$ patients, and 6 or more substances in $9(1.4 \%)$ patients. The active substances in 62 $(10.0 \%)$ patients could not be identified.

The drug groups included in the poisoning of 418 patients have been presented in Table 1. Fifty-one (8.2\%) of patients had been poisoned by preparations containing two or more active substances, which were anti-flu drugs (different combinations of paracetamol, decongestants, antihistamines and antitussives) in $46(7.4 \%)$ patients, anti-migraine drugs in $4(0.6 \%)$ patients, and anti-ulcer drugs in $2(0.3 \%)$ patients. The percentages were calculated considering a total of 418 patients. The sum of percentages was over 100 , since there were patients poisoned with multiple drugs. The total number of pills used by $446(71.6 \%)$ patients in the drug- 
Table 2. Patient Group Properties According to the Type of Poisoning

\begin{tabular}{|c|c|c|c|c|}
\hline & $\begin{array}{l}\text { Suicidal } \\
(n=489)\end{array}$ & $\begin{array}{l}\text { Accidental } \\
(n=120)\end{array}$ & $\begin{array}{l}\text { Overdose drug use } \\
(n=14)\end{array}$ & $\begin{array}{l}\text { Total } \\
(n=623)\end{array}$ \\
\hline \multicolumn{5}{|l|}{ Gender } \\
\hline Male & $114(23.3)$ & $57(47.5)$ & $7(50.0)$ & $178(28.6)$ \\
\hline Female & $375(76.7)$ & $63(52.5)$ & $7(50.0)$ & $445(71.4)$ \\
\hline \multicolumn{5}{|l|}{ Age groups } \\
\hline$\leq 15$ & $44(9.0)$ & $6(5.0)$ & $2(14.3)$ & $52(8.3)$ \\
\hline $16-20$ & $190(38.9)$ & $12(10.0)$ & $3(21.4)$ & $205(32.9)$ \\
\hline $21-30$ & $156(31.9)$ & $22(18.3)$ & $2(14.3)$ & $180(28.9)$ \\
\hline $31-40$ & $65(13.3)$ & $23(19.2)$ & $1(7.1)$ & $89(14.3)$ \\
\hline $41-50$ & $21(4.3)$ & $19(15.8)$ & $0(0.0)$ & $40(6.4)$ \\
\hline $51-60$ & $4(0.8)$ & $12(10.0)$ & $0(0.0)$ & $16(2.6)$ \\
\hline$\geq 61$ & $9(1.8)$ & $26(21.7)$ & $6(42.9)$ & $41(6.6)$ \\
\hline \multicolumn{5}{|l|}{ Medical history } \\
\hline No disease & $478(97.8)$ & $118(98.3)$ & $8(57.1)$ & $604(97.0)$ \\
\hline Systemic disease & $5(1.0)$ & $2(1.7)$ & $5(35.7)$ & $12(1.9)$ \\
\hline Psychiatric disease & $6(1.2)$ & $0(0.0)$ & $1(7.2)$ & $7(1.1)$ \\
\hline \multicolumn{5}{|l|}{ First center of admission } \\
\hline Other health centers & $188(38.4)$ & $27(22.5)$ & $3(21.4)$ & $405(65.0)$ \\
\hline Our emergency unit & $301(61.6)$ & $93(77.5)$ & $11(78.6)$ & $218(35.0)$ \\
\hline \multicolumn{5}{|l|}{ Route of poisoning } \\
\hline Oral & $488(99.8)$ & $43(35.8)$ & $10(71.4)$ & $541(86.9)$ \\
\hline Inhalation & $0(0.0)$ & $72(60.0)$ & $3(21.4)$ & $75(12.0)$ \\
\hline Dermal & $0(0.0)$ & $5(4.2)$ & $0(0.0)$ & $5(0.8)$ \\
\hline Parenteral & $1(0.2)$ & $0(0.0)$ & $1(7.1)$ & $2(0.3)$ \\
\hline \multicolumn{5}{|l|}{ Toxin } \\
\hline Drugs & $398(81.4)$ & $2(1.7)$ & $8(57.1)$ & $408(65.5)$ \\
\hline Pesticide/insecticide & $25(5.1)$ & $33(27.5)$ & $0(0.0)$ & $58(9.3)$ \\
\hline Carbon monoxide & $0(0.0)$ & $49(40.8)$ & $0(0.0)$ & $49(7.9)$ \\
\hline Foods & $0(0.0)$ & $28(23.3)$ & $0(0.0)$ & $28(4.5)$ \\
\hline Ronticides & $10(2.0)$ & $2(1.7)$ & $0(0.0)$ & $12(1.9)$ \\
\hline Corrosives & $2(0.4)$ & $1(0.8)$ & $0(0.0)$ & $3(0.5)$ \\
\hline Others & $3(0.6)$ & $5(4.2)$ & $5(35.8)$ & $13(2.1)$ \\
\hline With more than one group & $13(2.7)$ & $0(0.0)$ & $1(7.1)$ & $14(2.2)$ \\
\hline Unknown & $38(7.8)$ & $0(0.0)$ & $0(0.0)$ & $38(6.1)$ \\
\hline Duration of hospital stay (hours) & $38.7 \pm 38.4$ & $41.3 \pm 35.1$ & $39.6 \pm 30.5$ & $39.2 \pm 37.5$ \\
\hline \multicolumn{5}{|l|}{ Result } \\
\hline Discharge & $475(97.1)$ & $116(96.7)$ & $13(92.9)$ & $604(97.0)$ \\
\hline Transfer to normal room & $11(2.3)$ & $4(3.3)$ & $1(7.1)$ & $16(2.6)$ \\
\hline Exitus & $3(0.6)$ & $0(0.0)$ & $0(0.0)$ & $3(0.4)$ \\
\hline
\end{tabular}




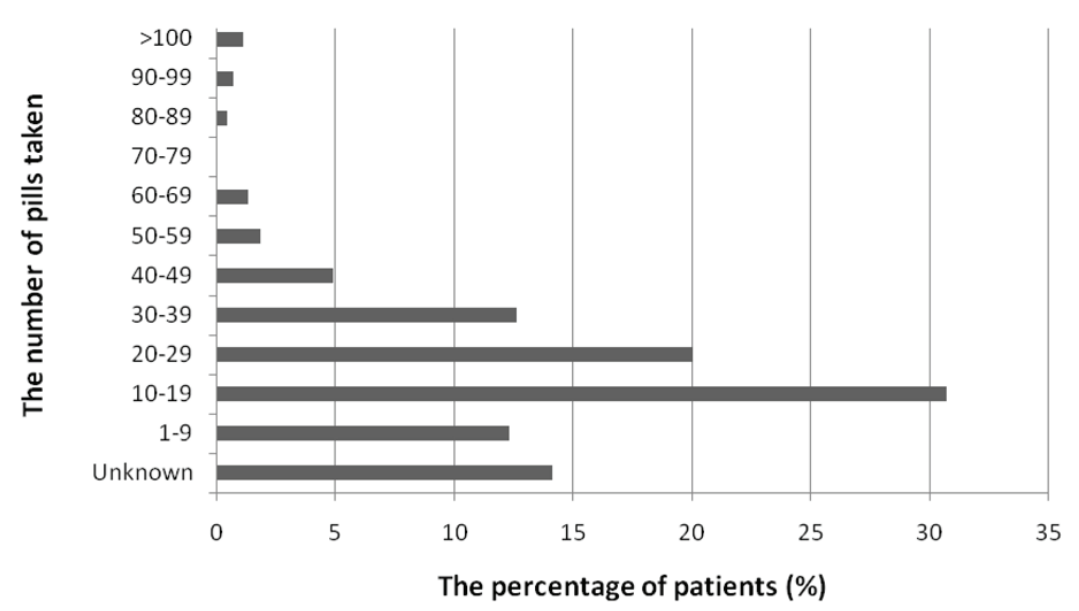

Figure 3. The total number of pills taken.

related poisoning group has been displayed in Figure 3.

The cause of poisoning was suicide in $489(78.5 \%)$ of patients, accidental in $120(19.3 \%)$ of them and overdose in $14(2.2 \%)$ of them. The number of women in the suicidal poisoning group (375 cases) was statistically significantly higher than the number of men $(114$ cases $)(P<0.001)$. According to age groups, $38.9 \%$ of the patients belonged to the 16 - 20 age group among the suicidal poisoning group, and $31.9 \%$ belonged to the $21-30$ age group $(\mathrm{P}<0.001)$. No accumulation was present in a certain age group for the patients in accidental or overdose groups $(\mathrm{P}>0.05)$. No significant difference was present between the lengths of stay in the hospital of the three groups $(\mathrm{P}>0.05)$. The patient group properties with regard to the cause of poisoning have been presented in Table 2.

Gastric lavage was performed and activated charcoal was administered to $316(50.7 \%)$ patients in our unit and to $192(30.8 \%)$ patients in other health centers. None of the interventions were applied to $115(18.4 \%)$ patients. Antidote was given to $196(31.5 \%)$ of 623 patients. The antidote was $\mathrm{N}$-acetylcysteine in $65(10.4 \%)$ patients, oxygen in $48(7.7 \%)$ patients, bicarbonate in $34(5.4 \%)$ patients and pralidoxime (PAM) in $18(2.9 \%)$ patients.

No complication was observed in $600(96.3 \%)$ of patients, while $11(1.8 \%)$ of them had rhabdomyolysis, 8 $(1.3 \%)$ of them had acute kidney failure, $2(0.3 \%)$ of them had seizures, $1(0.2 \%)$ of them had arrhythmia and $1(0.2 \%)$ of them had dystonia, 7 (1.1\%) of patients underwent hemodialysis, $5(0.8 \%)$ of them underwent hemoperfusion, and $1(0.2 \%)$ of them patient underwent plasmapheresis. Four $(0.6 \%)$ patients needed mechanical ventilation during the follow-up period, and $1(0.2 \%)$ patient underwent emergency endoscopy.

Six hundred and four (97.0\%) of patients were discharged from the toxicology unit at the end of the observational and treatment period, 16 (2.6\%) patients were referred to other wards and $3(0.4 \%)$ patients died. The mean obser- vation period of the patients in the toxicology unit was 39.2 \pm 37.5 (range 2 - 504) h.

\section{Discussion}

Poisoning is currently an important health problem worldwide. It is a frequent cause of admissions to emergency units in our country as well. Herein, we share our experiences regarding the cases of poisonings we followed up in the toxicology unit.

In our study, $71.4 \%$ of all the patients were women. In almost all of the studies from different regions of our country, women have shown the higher percentage of poisoning, which ranges between $53 \%$ and $73 \%$ [8-14]. In other countries, this range is $49-78 \%[4-6,15]$. The mean age was 28 in our study and $61.8 \%$ of all the patients were in the $16-30$ age group. Women in this age group reached a rate of $79 \%$. It has been reported that the rates of suicidal poisoning are high, especially in younger women in developing countries with patriarchal family structures such as Turkey [8-12, 1517].

It was observed that $78.5 \%$ of the poisoning cases were suicidal. Similar suicide attempt rates have been reported in different regions of our country, such as Adana, Kayseri and Istanbul $[8,9,11], 46-62 \%$ suicide attempt rates have been reported in Pakistan and Norway, whereas this rate has been reported to be approximately $90 \%$ in India, Iran and Romania [4-6, 15-17]. This variation between the regions and countries may reflect different suicidal inclinations of different societies and their choice of suicidal attempt methods. This subject should be investigated by further studies.

The most common substances involved in poisoning cases in our study were drugs $(65.5 \%)$, pesticides/insecticides $(9.3 \%)$ and carbon monoxide $(7.9 \%)$. Other studies from Turkey have reported the drugs as the most common poisoning agent as well [8-14]. Pesticide/insecticide poisonings are 
common in some regions of India and Sri Lanka, whereas alcohol is common in Norway and drugs are common in Romania, Iran and USA $[4,5,7,15,18,19]$. This shows that the agent of poisoning may differ according to the regional and sociocultural characteristics of a certain geography. The prevalence of use of toxic substances and easy availability are factors that affect the type of the exposed toxins.

Approximately $41 \%$ of accidental poisonings in our study were related to carbon monoxide. Carbon monoxide poisoning rates in our country have been reported to range between $2.1 \%$ and $10.2 \%$ [8-12]. Despite the years having passed and the organized programs for the awareness of the society, carbon monoxide poisoning remains an important cause of morbidity and mortality in winter.

The patients in the drug-related poisoning group were poisoned most frequently by analgesics $(57.2 \%)$ and antidepressants $(25.4 \%)$. The same situation is valid for some studies that have been conducted in Turkey [8, 9, 11, 20], while some others have reported an opposite ranking [11, 13, 21]. The most frequent agent of poisoning in USA is analgesics, whereas benzodiazepine poisoning is common in countries such as Iran, India and Norway [5, 6, 17, 19]. Analgesics and antidepressants, which are easily accessible and cheaper than other drug groups, are the most preferred drugs for suicides in Turkey, and that is in accordance with the results of our study.

In our study, $59.9 \%$ of the patients were poisoned by one active agent, while $13.8 \%$ were poisoned by two. The management of these patients is comparatively easy since the drug action and interactions are predictable. For the remaining $17 \%$ of patients, who were poisoned by 3 or more active agents, a careful follow-up is needed with possible aggressive decisions when necessary. The subject of principal importance here is the $10 \%$ of patients in whom the agent of exposure could not be determined by anamnesis or clinical findings. In emergency conditions, it is known that blood or urine toxicology tests are not valuable for the follow-up of most of the patients. However, the measurement of detectable compounds in blood such as paracetamol, salicylate and lithium, or in urine such as benzodiazepine and tricyclic antidepressants is important in the follow-up of patients and regulation of treatment protocols [22]. We believe that urine drug detection tests are necessary in the evaluation of the $10 \%$ of patients in whom anamneses could not be obtained and in patients with suicidal drug use in whom the anamneses are unreliable. Absence of urinary drug detection test was a deficiency in our study.

Hemodialysis and hemoperfusion were performed on $2.1 \%$ of the patients. In a study conducted in India, $2.9 \%$ of the patients were reported to have required hemodialysis [6]. The poisoning statistics of 2010 in USA show that $0.4 \%$ of the hospitalized poisoning cases had undergone either hemodialysis or hemoperfusion treatments [19]. Recently, extracorporeal treatments are being successfully used in the management of poisonings. Thus, we believe that toxicology units should possess the proper equipment.

In our study, no complication was observed on the follow-up of $96.3 \%$ of the patients, and the mortality rate observed was $0.4 \%$. Mortality rates that have been reported from different cities of Turkey are as follows: $2.6 \%$ in Adana, $0.7 \%$ in Istanbul, 5.8\% in Sanliurfa, 1.6\% in Kayseri and $0 \%$ in Ankara $[8-11,21]$. The mortality rates from other countries have been reported as: $2.3 \%$ in Iran, $0.8 \%$ in Norway and $2.8 \%$ in India $[5,6,17]$. The high mortality rates observed in regions with more widespread pesticide/insecticide poisonings such as Adana and India, are as expected. In our region, poisonings are usually related to less toxic agents such as analgesics or antidepressants, and thus, our mortality rates are rather low. Furthermore, we believe that rapid transfer of the patients to the toxicology unit following the first stabilization decreased our morbidity and mortality rates.

All of the studies concerning poisoning cases show that poisoning is a serious medical problem. Although different etiological and demographic data are observed from different regions of a country or from different countries, the only subject of consensus is that the poisoned patient needs a special management algorithm beginning with admission to the emergency unit until their discharge. Therefore, special toxicology units with ample facilities should be constructed in order to provide aggressive medical support when needed and a careful follow-up. The health policies of developed countries which support the construction of such toxicology units should be followed up in developing countries such as Turkey as well.

\section{Conclusion}

The most frequent group of poisoned patients comprised women in the 16 - 30 age group in our study. The suicidal poisoning cases were $78.5 \%$ of the cases. The most frequent causes of poisoning were drugs, pesticides/insecticides and carbon monoxide. Health and education policies at a national level are needed in order to prevent this medicosocial problem. Furthermore, specially equipped toxicology units should be constructed for the treatment and follow-up of poisoned patients in order to decrease the morbidity and mortality to a significant extent.

\section{Limitations}

Since our study was retrospective, there were no data on some important information such as marital status, reasons for suicide attempts, and whether these attempts were reactional or not. Although our toxicology unit is unique in our region, poisoning cases are being followed up in different wards of other hospitals as well. Therefore, our study does not demonstrate the real frequency of poisoning cases in our region. 


\section{References}

1. National Center for Injury Prevention and Control, Centers for Disease Control and Prevention. WISQARS Nonfatal Injury Reports 2001-2011. Available at: http:// webappa.cdc.gov/sasweb/ncipc/nfirates2001.html. Accessed Nov 12, 2012.

2. National Center for Injury Prevention and Control, Centers for Disease Control and Prevention. WISQARS Fatal Injury Reports 1999-2010. Available at: http://webappa.cdc.gov/sasweb/ncipc/mortrate10_us.html. Accessed Nov 12, 2012.

3. National Center for Injury Prevention and Control, Centers for Disease Control and Prevention. WISQARS Leading Causes of Death 1999-2010. Available at: http:// webappa.cdc.gov/sasweb/ncipc/leadcaus10_us.html. Accessed Nov 12, 2012.

4. Sorodoc V, Jaba IM, Lionte C, Mungiu OC, Sorodoc L. Epidemiology of acute drug poisoning in a tertiary center from Iasi County, Romania. Hum Exp Toxicol. 2011;30(12):1896-1903.

5. Lund C, Teige B, Drottning P, Stiksrud B, Rui TO, Lyngra M, Ekeberg O, et al. A one-year observational study of all hospitalized and fatal acute poisonings in Oslo: epidemiology, intention and follow-up. BMC Public Health. 2012;12:858.

6. Singh O, Javeri Y, Juneja D, Gupta M, Singh G, Dang R. Profile and outcome of patients with acute toxicity admitted in intensive care unit: Experiences from a major corporate hospital in urban India. Indian J Anaesth. 2011;55(4):370-374.

7. de Silva VA, Senanayake SM, Dias P, Hanwella R. From pesticides to medicinal drugs: time series analyses of methods of self-harm in Sri Lanka. Bull World Health Organ. 2012;90(1):40-46.

8. Satar S, Seydaoglu G, Akpinar A, Sebe A, Karakoc E, Gumusay U, Yilmaz M, et al. Trends in acute adult poisoning in a ten-year period in Turkey: factors affecting the hazardous outcome. Bratisl Lek Listy. 2009;110(7):404-411.

9. Avsarogullari L, Senol V, Akdur O, Akin A, Durukan P, Ozkan S. Characteristics of acute adult poisonings in a university hospital emergency department in central Turkey: a three-year analysis. J Pak Med Assoc. 2012;62(2):129-133.

10. Cengiz M, Baysal Z, Ganidagli S, Altindag A. Characteristics of poisoning cases in adult intensive care unit in
Sanliurfa, Turkey. Saudi Med J. 2006;27(4):497-502.

11. Tufekci IB, Curgunlu A, Sirin F. Characteristics of acute adult poisoning cases admitted to a university hospital in Istanbul. Hum Exp Toxicol. 2004;23(7):347-351.

12. Akkose S, Bulut M, Armagan E, Cebicci H, Fedakar R. Acute poisoning in adults in the years 1996-2001 treated in the Uludag University Hospital, Marmara Region, Turkey. Clin Toxicol (Phila). 2005;43(2):105-109.

13. Goksu S, Yildirim C, Kocoglu H, Tutak A, Oner U. Characteristics of acute adult poisoning in Gaziantep, Turkey. J Toxicol Clin Toxicol. 2002;40(7):833-837.

14. Baydin A, Yardan T, Aygun D, Doganay Z, Nargis C, Incealtin $\mathrm{O}$. Retrospective evaluation of emergency service patients with poisoning: a 3-year study. Adv Ther. 2005;22(6):650-658.

15. Pajoumand A, Talaie H, Mahdavinejad A, Birang S, Zarei M, Mehregan FF, Mostafazadeh B. Suicide epidemiology and characteristics among young Iranians at poison ward, Loghman-Hakim Hospital (1997-2007). Arch Iran Med. 2012;15(4):210-213.

16. Patel MJ, Shahid M, Riaz M, Kashif W, Ayaz SI, Khan MS, Samdani AJ, et al. Drug overdose: a wake up call! Experience at a tertiary care centre in Karachi, Pakistan. J Pak Med Assoc. 2008;58(6):298-301.

17. Islambulchilar M, Islambulchilar Z, Kargar-Maher MH. Acute adult poisoning cases admitted to a university hospital in Tabriz, Iran. Hum Exp Toxicol. 2009;28(4):185190.

18. Bose A, Sandal Sejbaek C, Suganthy P, Raghava V, Alex R, Muliyil J, Konradsen F. Self-harm and self-poisoning in southern India: choice of poisoning agents and treatment. Trop Med Int Health. 2009;14(7):761-765.

19. Bronstein AC, Spyker DA, Cantilena LR, Jr., Green JL, Rumack BH, Dart RC. 2010 Annual Report of the American Association of Poison Control Centers' National Poison Data System (NPDS): 28th Annual Report. Clin Toxicol (Phila). 2011;49(10):910-941.

20. Mert E, Bilgin NG. Demographical, aetiological and clinical characteristics of poisonings in Mersin, Turkey. Hum Exp Toxicol. 2006;25(4):217-223.

21. Ozkose Z, Ayoglu F. Etiological and demographical characteristics of acute adult poisoning in Ankara, Turkey. Hum Exp Toxicol. 1999;18(10):614-618.

22. Kulig K, Ling LJ. General approach to the poisoned patient. In: Marx J (ed). Rosen's Emergency Medicine: Concepts and Clinical Practice (7th ed). 2010;19421947. 